\section{Przemyslaw Lisiński}

Received: 12 November 1998

Accepted: 5 January 2000

\section{P. Lisiński}

Department of Rehabilitation,

Karol Marcinkowski University

of Medical Sciences,

28 Czerwca 1956 135/147,

61-545 Poznan, Poland

Tel.: +48-61-8310219,

Fax: +48-61-8334421

\section{Surface EMG in chronic low back pain}

Sixty-two patients with CHLBP were examined (30 men and 32 women, mean age $41 \pm 8$ years). The control group consisted of 31 people without back problems (16 men and 15 women, mean age $39 \pm 6$ years). The statistical values of mean amplitude, mean density and upper amplitude were found to be higher in the control group at the T7 level. At the L4 level, mean amplitude, mean density, background amplitude, background density and upper amplitude were significantly higher in control group. The findings of this study show that (1) dysfunction of the erector spinae plays a significant role in CHLBP, and (2) this process applies to small and large motor units, but the character of these changes is different in particular muscles. Surface EMG is an objective, non-invasive method of examining function of the erector spinae in the author's opinion.

Key words Chronic low back pain . Dysfunction of the erector spinae . EMG

\section{Introduction}

Chronic low back pain (CHLBP) occupies first place among factors restricting people's life activity under the age of $45[3,7,13]$. Frequency of CHLBP occurrence oscillates between 60 and $80 \%$ [6]. One of the most impor- tant issues that should be taken into consideration is the question of where this problem originates. So far, there are about 500 hypotheses about the origin of CHLBP [5, $9,29]$. One of the most significant points to dysfunction of the erector spinae $[1,2,8,10]$. This muscle is particularly important because the erector spinae actively counteracts external overloads acting on the spine in static and 
dynamic conditions $[12,21]$. It also has the largest transsection area and the shortest arm of activity in relation to bony elements of the spine [25]. Theoretically there are two possible causes of dysfunction of this muscle. The first is traumatic damage to one of the spine's structures (nucleus pulposus, for example), leading to acute low back pain that prevents the patient from living an active life. Such a situation can lead to atrophy of the erector trunci and associated dysfunction [17, 24, 30]. The second possible cause is prolonged conditions of overload, under which the the erector spinae is obliged to function isometrically,leading to atrophy [11]. Precisely the question of whether dysfunction of the erector spinae is a cause or the result of low back pain is still open.

Nowadays we have a variety of methods of examining this muscle $[4,14,16,22]$. One of them is examination of the change in the frequency distribution of EMG signal. This is a valuable, non-invasive technique for evaluating the development of local muscle fatigue during the maintenance of an isometric contraction [19, 20]. A modification of this method is automatic analysis of the interference pattern (IP) that represents muscle activity during maximum voluntary effort [15]. This analysis requires accurate time measurement $(1,2$ or $3 \mathrm{~s})$ and measures parameters that are directly related to different motor units' (MUs) activity contributing to the interference pattern.

\section{Aim of the study}

The study aimed to evaluate whether automatic analysis of the IP done by surface EMG is a good method for identifying dysfunction of erector spinae in CHLBP cases.

\section{Materials and methods}

Patients

Sixty-two patients with the clinical diagnosis of CHLBP were examined (30 men and 32 women, mean age $41 \pm 8$ years). The control group consisted of 31 people without back problems (16 men, 15 women, mean age $39 \pm 6$ years). Each subject was informed of the purpose and potential risk of the study before his or her written voluntary consent was obtained. The study was approved by the local Medical Ethics Committee.

\section{Methods}

All participants underwent EMG of the longissimus thoracis muscle (T7) and the multifidus muscle (L4). Following appropriate skin preparation to reduce skin impedance, $10-\mathrm{mm}$ surface electrodes were attached to the skin overlying the erector spinae at the levels of the T7 and L4 vertebrae, approximately 3-4 cm from the midline of the back. These electrodes were located unilaterally on the right side. A reference electrode was attached to the skin overlying the right arm. DISA-Electronic apparatus was used, connected to a PC equipped with the EMG-LAB programme, which allowed registration, transformation, amplification, analysis and projection of results on-line. The summary of the complete exam- ination is presented in Table 1 in the form of statistical values of parameters such as mean amplitude (M.A.), mean density (M.D.), background amplitude (B.AMP.), background density (B.DENS.), upper amplitude (U.AMP.), and upper density (U.DENS.).

Each subject was placed in a prone position on an examination couch with the lower body, from the superior border of the iliac crest downward, strapped to the couch [4]. With hands touching the ears, elbows out to the side and level with the trunk, and head in a neutral position, the subject was requested to maintain the unsupported upper body in a horizontal position for $2 \mathrm{~s}$. Each examination was performed twice. The first one was a practice for the patient, with the measurements being taken from the second.

\section{Statistics}

Data are presented as mean and standard deviation (SD). Statistical analysis was carried out using the Student $t$-test. Statistical significance was accepted at the 5\% level.

\section{Results}

Statistical mean values are shown in Table 1. Mean amplitude, mean density and upper amplitude are higher in the control group at T7. Results from the multifidus muscle (L4) are somewhat different. Mean amplitude, mean density, background amplitude, background density and upper amplitude have significantly higher values in the control group in relation to patients.

\section{Discussion}

The recently developed EMG-LAB software allows analysis of the interference pattern (IP) during maximum voluntary effort, and determination of the parameters of different MU size, their quantity and intensity of recruitment. The automatic analysis requires accurate time measurement $(1,2$ or $3 \mathrm{~s})$. The global assessment of IP is based on the two parameters of mean amplitude and mean density. The most prominent activity of the IP [15], termed "Background", is generated in most cases by complex or polyphasic low-threshold MUs, the MUAPs for which are characteristic for a given muscle and its electrophysiological state. The other clinically important information concerns the high level of MU activity obtained from upper centile measurement. "Upper" activity is generally generated by high-threshold MUs [15].

Mean amplitude corresponds under some conditions to the number of muscle fibers in MUs, the diameter of muscle fibers and synchronicity of their contraction. Mean density can reflect the number of MUs and their frequency of recruitment [15]. The erector spinae is a "postural" muscle, which is responsible for maintenance of correct posture. Predominant activity is generated by slow twitch fibers in this kind of muscle. So-called "background" amplitude is correlated with the number of muscle fibers in small MUs, the diameter of these fibers and synchronicity of their contraction. Background density corresponds with 
Table 1 Results of the automatic analysis of interference pattern (M.A. mean amplitude, B.DENS. background density, M.D. mean density, UAMP. upper amplitude, B.AMP. background amplitude, UDENS. upper density)

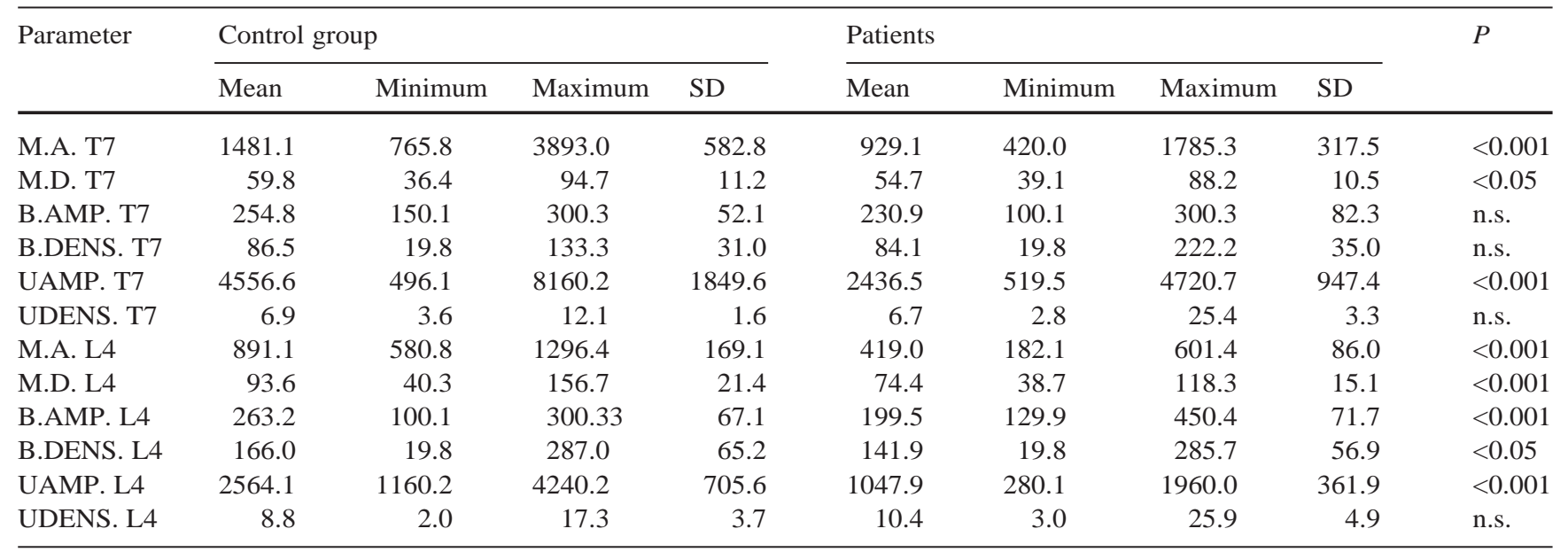

the number of small MUs and their frequency of recruitment. A small MU consists of slow twitch fibers type I.

Upper amplitude and upper density corresponds with these same parameters, but in large motor units, which consist of fast twitch fibers type II [23, 27].

Results from the T7 level may suggest that in cases of CHLBP there is a drop in the number of muscle fibers in small and large MUs (differences in mean amplitude between patients and control group); furthermore, the diameter of the muscle fibers is smaller and synchronicity of their contraction lower among patients. Moreover, the number of MUs is smaller among patients and their frequency of recruitment is worse. All these all changes apply particularly to the fast twitch fibers type II, located in large MUs. Results from the L4 level suggest changes affect small MUs more than large ones.

The number of units, number of fibers, synchronicity of their contraction and level of their frequency of recruitment are all lower among CHLBP patients. The character of these changes is similar in large MUs, without a drop in their number or lowering of their frequency of recruitment (see Table 1).

Results of this study demonstrate that in cases of CHLBP, bioelectrical changes of erector spinae activity are present. This method makes it possible to examine the general activity of the erector spinae over a few seconds.
Differences in results between T7 and L4 can be explained by difference in the distribution of two main sorts of fibers in these parts of the erector spinae [18, 26, 28]. In the lumbar region the relative area of the muscle occupied by type I fibers is significantly greater than that in the thoracic region. Besides this, the diameter of slow twitch fibers is larger than that of fast twitch fibers. No relation was found between values of curvature of the lumbar spine and the value of any of the electrophysiological parameters in the global IP examination. All values of the lumbar spine curvature were within the limits of normal values.

\section{Conclusions}

1. Dysfunction of the erector spinae plays a significant role in CHLBP.

2. This process refers to small and large motor units, but character of these changes is different in particular muscles.

3. Surface EMG is an objective, non-invasive method of examining function of the erector spinae in my opinion.

\section{References}

1. Addison R, Schultz A (1980) Trunk strengths in patients seeking hospitalization for chronic low back disorders. Spine 5:539
2. Alston W, Carlson KE (1966) Quantitative study of muscle factors in the chronic low back syndrome. J Am Geriatr Soc 14:1041-1047

3. Battié M, Bigos S (1990) The role of spinal flexibility in back pain complaints within industry. Spine 15:768-773
4. Blering-Sörensen F (1984) Physical measurements as risk indicators for low back trouble over a one year period. Spine 9:106-119 
5. Buckle P (1987) A multi-disciplinary investigation of factors associated with low back pain. Thesis, Cranfield Institute of Technology, Bedfordshire

6. Cassidy JD, Wedge JH (1988) The epidemiology and natural history of low back pain and spinal degeneration. In: Kirkaldy-Willis WH (ed) Managing low back pain, 2nd edn. Churchill Livingstone, Edinburgh, pp 3-15

7. Coste J, Paolaggi J (1992) Classification of nonspecific low back pain. Psychological involvement in low back pain. Spine 17:1028-1037

8. Crisco J, Panjabi M (1991) The intersegmental muscles of the lumbar spine. A biomechanical model comparing lateral stabilizing potential. Spine 16:793-799

9. D'Orazio B (1993) Back pain rehabilitation. Andover Medical Publishers, pp 17-21

10. Hansen F, Bendix T (1993) Intensive, dynamic back-muscle exercises, conventional physiotherapy or placebocontrol treatment of low back pain. Spine 18:98-108

11. Kirkaldy-Willis WH (ed) (1988) Managing low back pain, 2nd edn. Churchill Livingstone, Edinburgh, pp 49-75

12. Klein AB, Roy SH (1991) Comparison of spinal mobility and isometric trunk extensor strength to EMG spectral analysis in identifying low back pain. Phys Ther 71:445-454
13. Kohles S, Barnes D (1990) Improved physical performance outcomes after functional restoration treatment in patients with chronic low back pain. Spine 15:1321-1324

14. Kondraske GV, Carmichael T (1987) Myoelectric spectral analysis and strategies for quantifying trunk muscular fatigue. Arch Phys Med Rehabil 68:103110

15. Kopec J (1992) EMG-LAB computer system for routine electromyography. Electromyogr Clin Neurophysiol 33:173-184

16. Krause M, Zielifiski M (1992) Zastosowanie elektromiografii do rozpoznawania zespolów bólowych ledzwiowo-krzyzowych. Med Pr 43:499-504

17. Macintosh J, Bogduk N (1991) The attachments of the lumbar erector spinae. Spine 16:783-792

18. Mannion FA, et al (1997) Muscle fiber size and type distribution in thoracic and lumbar regions of erector spinae in healthy subjects without low back pain: normal values and sex differences. J Anat 190:505-513

19. Mannion FA, et al (1997) The use of surface power spectral analysis in the evaluation of back muscle function. J Rehabil Res 34:427-439

20. Mannion FA, Dolan P (1994) Electromyographic median frequency changes during isometric contraction of the back extensors to fatigue. Spine 19:1223-1229

21. McKenzie R (1984) Prophylaxis in recurrent low back pain. N Z Med J 76: 484
22. Nordin M, Kahanovitz N (1987) Normal trunk muscle strength and endurance in woman and the effect of exercises and electrical stimulation. Spine 12:105-118

23. Person R (1986) Teoretyczne podstawy elektrorniografii klinicznej. In: Hausmanowa-Petrusewicz I (ed) Elektromiografia kliniczna. PZWL, Warsaw, pp 35-48

24. Risch S, Norrell N (1993) Lumbar strengthening in chronic low back pain patients. Spine 18:232-238

25. Schultz A, Warwick DN (1974) Mechanical properties of human lumbar spine motion segments. 1. Responses in flexion, extension, lateral bending and torsion. J Biomech Eng 101:46-52

26. Sirca A (1985) The fiber type composition of thoracic and lumbar paravertebral muscles in man. J Anat 141:131137

27. Solomonow M, Baratta R (1990) Electromyogram power spectra frequencies associated with motor unit recruitment strategies. J Appl Physiol 68:1177

28. Sulemena CA (1972) Topische Unterschiede in der enzyrnhistologischen Zusammensetzung der Skelettmuskulatur. J Neurol Sci 16:433-444

29. Svensson HO, Vedin A (1983) Low back pain in relation to other diseases and cardiomuscular risk factors. Spine $8: 277$

30. Tucci J, Carpenter D (1992) Effect of reduced frequency of training and detraining on lumbar extension strength. Spine 17:1497-1501 